\title{
Architecture, Astronomy and Sacred Landscape in Ancient Egypt by Giulio Magli
}

\section{Kim Williams}

Archaeoastronomer Giulio Magli is no stranger to readers of the Nexus Network Journal. He began sharing his research with us in 2005, and has authored or co-authored several papers $(2005,2006,2007,2009 a)$, and most importantly, was guest editor of a special issue of the $N N J$ devoted to architecture, mathematics and archaeoastronomy (NNJ 15, 3,2013 ), which resulted from his chairing of a session on that theme during the Nexus 2012 conference in Milan. The contributions to the $N N J$ have all been characterised by the hallmarks that distinguish his new monograph, Architecture, Astronomy and Sacred Landscape in Ancient Egypt (Cambridge University Press, 2013): careful, original research, a clear exposition, and a passion for the discipline.

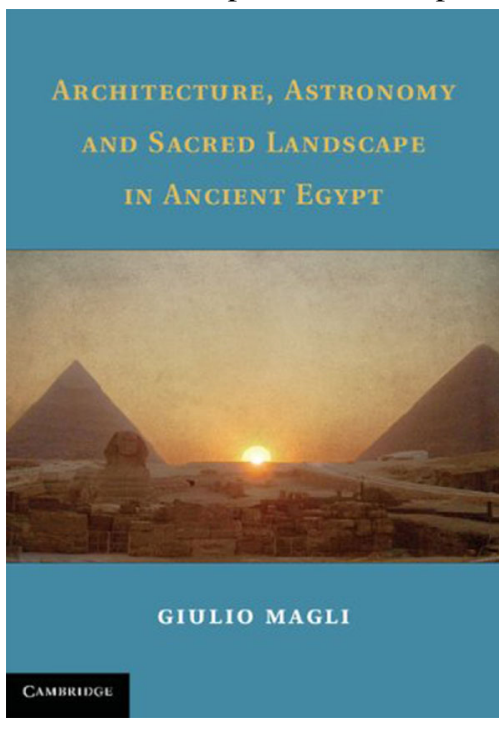

K. Williams $(\bowtie)$

Corso Regina Margherita, 72, 10153 Turin, TO, Italy

e-mail: kwb@kimwilliamsbooks.com 
First of all, what is archaeoastronomy? "Modern archaeoastronomy is the science devoted to the study of the knowledge of the sky in ancient times as reflected in architecture and landscape" (2013: 2). Magli then goes on to explain that the primary concern of the Egyptian culture was to preserve and transmit a sense of Maat, or cosmic order, which was intimately related to celestial cycles: sunrise and sunset, the succession of hours, days, months and years, the appearance of key stars. Analysing Egyptian monuments from this point of view allows us to read the buildings, and indeed entire landscapes in light of what the Egyptians knew, not just what they did.

Magli says, "(Maat was) a mixture of order, truth and justice, but it is easier to say just that Maat was the opposite of Chaos: it was regularity" (2013: 10). Knowledge of the sky allowed the Egyptians to impose a regularity on their architecture and urban planning that linked landscape and objects to a larger context that was believed to be eternal. This leads to the concept of "sacred landscape", where the sacred quality is endowed by a connection of the landscape with the cosmos:

Cosmos gives order, and order transforms space into sacred space. First of all, cosmos provides orientation. A privileged axis, the axis mundi, springs naturally from the fact that the stars rotate around the celestial pole. It is the axis of the world that allows the existence of directions, the "breaking" of spatial homogeneity. The direction determined at the horizon by projecting the axis is naturally privileged for the simpler reason that anyone is able to determine it. This privileged direction is associated with the stars and the pole, but also with the sun at culmination to the south. The orthogonal, east to west direction can be found connecting the rising and setting points of the sun or of a star over a flat horizon. In short, the "world of man" is naturally divided into four equal quarters in accordance with the celestial cycles. As a result of this "cosmisation" process, the space itself become ordered, ... becomes sacred space (2013: 21).

With this as a premise, what follows is an analysis of the major monuments and sites of ancient Egypt from the first dynasty tombs in Saqqara to tombs of the kings of the twentieth dynasty in the valley of the kings. Thus there are revealing discussion of the all of the major monuments: the Step Pyramid of Djose in Saqqara; the Bent Pyramid in Dahshur; the Great Pyramid, and those of Khafra and Menkaura in Giza; the Pyramid of Sahura in Abusir; the Temple of Luxor, the Temple of Ramesses II at Abu Simbel. Magli explains how striking aspects of individual monuments are related to what was happening in the sky. For instance, the holes in a sealed chamber, or Serdab, that houses a statue of Djoser are positioned in line with the eyes of the statue, so that if the viewer looks into them, he finds himself face-toface with the Pharaoh. Of greater interest, however, is that the statue (and the holes through which he looks out) are oriented so that the Pharaoh was looking at points through which two circumpolar stars transited (2013: 51). In the Great Pyramid of Giza, previously unexplained shafts within the mass of the pyramid are found to be governed by astronomical alignments (2013: 80). 
Equally intriguing are the analyses of the larger landscapes and complexes in which the individual monuments are located. This makes clear the overarching order found in the sites of Saqqara, Sahshur, Giza and Abusir, and shows how, viewed collectively, the individual monuments create a kind of Gestalt effect.

This new book is carefully composed as a scientific text, meaning that sources are cited where required, data is backed up, and the whole is accompanied by notes, bibliography and an index (that actually works!), but it is as interesting and enjoyable to read as the best works of popular science. Readers unfamiliar with archaeoastronomy are given the information they need along the way, in the form of "boxes" interspersed between the main chapters; these touch on topics such as "The apparent motion of the celestial bodies in the sky" and "solar eclipses". Further information is given in the Appendices: table about azimuth values and dimensions of the pyramids and other monuments, and a chronology of the Egyptian dynasties. This means that all the information the reader needs is at his or her fingertips, yet the flow of the main discussion is not interrupted by providing it in the main body of the text.

If the reader requires more detailed explanation of how the Egyptians "read" the sky and made the necessary calculations to achieve their extraordinary effects, all that is needed is found in Magli's other recent publication, Mysteries and Discoveries of Archaeoastronomy (2009b). There an Appendix entitled "The Sky with the Naked Eye" (2009b) provides a somewhat more detailed version of the explanation given in Box 2 of the new book (2013: 25-30), and also describes the process for making measurements for archaeoastronomy in fieldwork, which is a fascinating glimpse of the actual practice of carrying out this research. The older book takes a broader overview of the discipline, covering sites that range from Newgrange to Malta to Chaco Canyon to Egypt to the Easter Islands, and also has the advantage of a section of beautiful colour photographs that bring the sites to life.

The ruins and relics left to us by ancient civilisations are fascinating because they speak to us from the dawn of time, in a language that we can't understand but that in some way we still recognise as own, that is, human. All the products of human building - architecture, but also sculptures - are manifestations of man responding to his environment. Sometimes that environment-or at least the remains of what have survived to the present day-is strictly elemental: the sand of the desert, the weather-beaten shores of the ocean, the sculpted rock formations of mesa and landscapes once covered by lava. The one element always present in all environments (even our own, in modern cities, although we seldom give it much thought) is the sky. Through the lens of archaeoastronomy we are able to decipher the relationship between man and the sky, and thus have one key to the language of ancient civilisations.

Keys are useless, however, if we don't understand them, and Giulio Magli is a master of clarity. For specialists and non-specialists of archaeoastronomy, as well as those interested in the civilisation of ancient Egypt, Architecture, Astronomy and Sacred Landscape in Ancient Egypt will be not only a valuable reference, but also a good read. 


\section{References}

Magli, Giulio. 2005. Mathematics, astronomy and sacred landscape in the Inca Heartland. Nexus Network Journal 7(2): 22-32.

Magli, Giulio. 2006. The acropolis of alatri: architecture and astronomy. Nexus Network Journal 8(1): $5-16$.

Magli, Giulio. 2007. Non-orthogonal features in the planning of four ancient towns in central Italy. Nexus Network Journal 9(1): 71-92.

Magli, Giulio, and Khufu Akhet. 2009. Archaeo-astronomical hints at a common project of the two main pyramids in Giza Egypt. Nexus Network Journal 11(1): 35-50.

Magli, Giulio. 2009. Mysteries and discoveries of archaeoastronomy. New York: Copernicus Books.

Magli, Giulio. 2013. Architecture, astronomy and sacred landscape in ancient Egypt. Cambridge: Cambridge University Press.

Kim Williams received her degree in Architectural Studies from the University of Texas in Austin, and is licensed as an architect in New York State. Her apprenticeship was done in the offices of Philip Johnson in New York. She became interested in mathematics and architecture while writing Italian Pavements: Patterns in Space (Houston: Anchorage Press, 1997) about the role of decorated pavements in the history of Italian architecture. In 1996 she began the international conference series "Nexus: Architecture and Mathematics". In 1999 she founded the Nexus Network Journal to provide a dedicated venue for scholarly research in architecture and mathematics. In 2000 she founded Kim Williams Books, an independent press for books about architecture and mathematics. Kim has published many articles in scholarly journals on the use of mathematical principles in architecture, including The Mathematical Intelligencer and Leonardo. Her drawings have been displayed in both group and solo exhibits. She has participated in numerous international conferences. Her latest book, co-edited with Michael Ostwald, is the 2-volume Architecture and Mathematics from Antiquity to the Future (forthcoming from Birkhäuser, 2014). 